\title{
Critical soft factors for card-based production systems implementation: a multi-method study
}

Gustavo Bagni', Moacir Godinho Filho¹, Guilherme Luiz Tortorella², Charbel José Chiappetta Jabbour ${ }^{3}$

${ }^{1}$ Federal University of São Carlos - UFSCar, São Carlos, SP, Brazil.

${ }^{2}$ Federal University of Santa Catarina - UFSC, Florianópolis, SC, Brazil.

${ }^{3}$ Montpellier Business School, Montpellier, France.

How to cite: Bagni, G., Godinho Filho, M., Tortorella, G.L. et al. (2021), "Critical soft factors for card-based production systems implementation: a multi-method study", Brazilian Journal of Operations \& Production Management, Vol. 18, No. 4, e20211128. https://doi.org/10.14488/BJOPM.2021.020

\begin{abstract}
Goal: Although card-based systems are a mature topic in literature, studies have focused mainly on how to optimize parameter of each system. The influential of human factors in the implementation of those systems have rarely been evaluated. Therefore, this study aims to understand what are the critical soft factors for a successful card-based systems implementation.

Design / Methodology / Approach: A multi-method study is used in this research, combining systematic literature review, longitudinal case study, content analysis, interviews with experts and validations with two different groups.

Results: The paper proposes a list of 15 soft factors critical to a successful implementation of cardbased systems categorized in a "house framework" according to the level of analysis each factor is included.

Limitations of the investigation: A single case study, although longitudinal, was conducted to proposed the list of factors. Therefore, further studies should be conducted to adapt the list to other organizations and contexts.

Practical implications: Following the proposed list of factors, managers can increase the success in implementing a card-based system in their organizations.

Originality / Value: This study combines different research methods in a unique way, since in the researchers' view, an individual method was not sufficient to answer the proposed research question. Moreover, the case study reported a failure implementation of a card-based system, a rare addition to literature which mainly presented success cases.
\end{abstract}

Keywords: Card-Based System; Production Control System; Kanban; Soft Factors; Empirical Study.

\section{INTRODUCTION}

Production Control Systems (PCS) regulates information and materials flows throughout the factory and supply chains (Karrer et al., 2012). Among PCS, card-based systems, like Kanban, CONWIP, POLCA and COBACABANA are the most studied and implemented ones (Liberopoulos and Dallery, 2000). In this class of PCS, the communication and control of materials on the shop floor is carried out by cards, which represent the production orders.

The systems, however, differ in how they carry out this control. For example, while Kanban, CONWIP and POLCA control stock levels, COBACABANA controls workload released to the shop floor. Moreover, in COBACABANA, orders release are centralized in the scheduler,

Financial support: None.

Conflict of interest: The authors have no conflict of interest to declare.

Corresponding author: gustavobagni@uol.com.br

Received: 19 Dec 2020.

Approved: 15 Jan 2021.

Editor: Julio Vieira Neto. 
while in kanban, CONWIP and POLCA usually decisions are decentralized. The systems differ also on how stock is controlled in the shop floor. In kanban it is possible to control the level of stock of each product in each resource or production stage, while in CONIWP it is possible only to control the stock in the whole shop floor

An extensive literature on the most traditional card-based systems is available in literature, while more recent systems have been less explored (Bagni et al., 2020). However, although it is considered a mature topic in literature, most papers have focused on mathematical approaches to optimize the parameters of each system (Pons, 2010; Hendry et al., 2013). Implementation, however, remains a complex problem and many organizations still have many difficulties in this process (Marodin and Saurin, 2013). Therefore, it is interesting to assess what these difficulties are and propose way to overcome them so that companies can achieved the theoretical benefits that card-based systems propose.

In card-based systems, the strong human influence on the operation of the PCS increases the complexity of implementation, as it is necessary to plan how to communicate, train, engage and motivate employees as they are a central element of implementation success (Hendrick and Kleiner, 2001; Salem et al., 2006; Liu and Huang, 2009). However, apart from Pons (2010), soft factors have been rarely studied in the specific context of card-based systems (Marodin and Saurin, 2013).

Based on the scarcity of studies and, consequently, the low understanding of this topic, a research question arises: "What are the critical soft factors for a successful card-based systems implementation?"

In response to this question, the objective of this is study is to propose a list of critical soft factors. Through a Systematic Literature Review (SLR) and a longitudinal case study (LCS), we identified many problems associated with card-based system implementation. Afterwards, a content analysis using the summarizing technique was conducted to classify the collected information, constructing a list of 14 soft factors, as well as defining the meaning of each of them. Finally, the list was reviewed by 6 experts, adding a fifteenth factor, and it was validated by company's employees and the experts.

The final list contains factors as diverse as management support, implementation during low demand period and card's material quality. In this list, we maintained factors generic, not including specific factors suitable for particular environments. Therefore, additional factors can be included for each individual implementation. In terms of research, we seek to highlight the importance of soft factors on card-based system implementation, asking for more studies in this field. In terms of practice, this list can support companies to increase the success in implementing card-based systems, and that managers know in advance which soft factors they should focus their attention during such implementation process.

\section{PROPOSED RESEARCH METHOD}

This article uses a combination of methods to consolidate a list of critical soft factors to the implementation of card-based systems, as shown in Figure 1. The proposed method is comprised of six steps, in which the first two steps were conducted in parallel. In step (i), a SLR was conducted to identify empirical studies that mention difficulties and problems related to soft factors during card-based system implementation. In step (ii), we conducted an inductive longitudinal case study in a transnational manufacturer which has failed to implement kanban in its value stream, in order to identify more difficulties related to effect of soft factors on cardbased systems implementation.

Based on the information collected in the previous steps, the next step aimed at classifying the difficulties and problems of the implementation of card-based systems according to each factor. This was done by carrying out a content analysis (step iii) using the summarizing technique (Haapanen and Tapio, 2016). After that, this list was revised by 6 experts carefully selected from three different areas: academia, industry and consultancy. Individually, they analysed if the name and description of each factor are clear, as well as if they represent a critical barrier to a card-based system implementation (step iv). Finally, the 
list was evaluated and discussed with three employees from the focus company who had taken part in the research (step v) and with the six experts (step vi). Such analysis allowed the validation of each factor's name and description, validating their relevance for a successful card-based systems implementation. The specificities of each step are detailed in the following subsections.

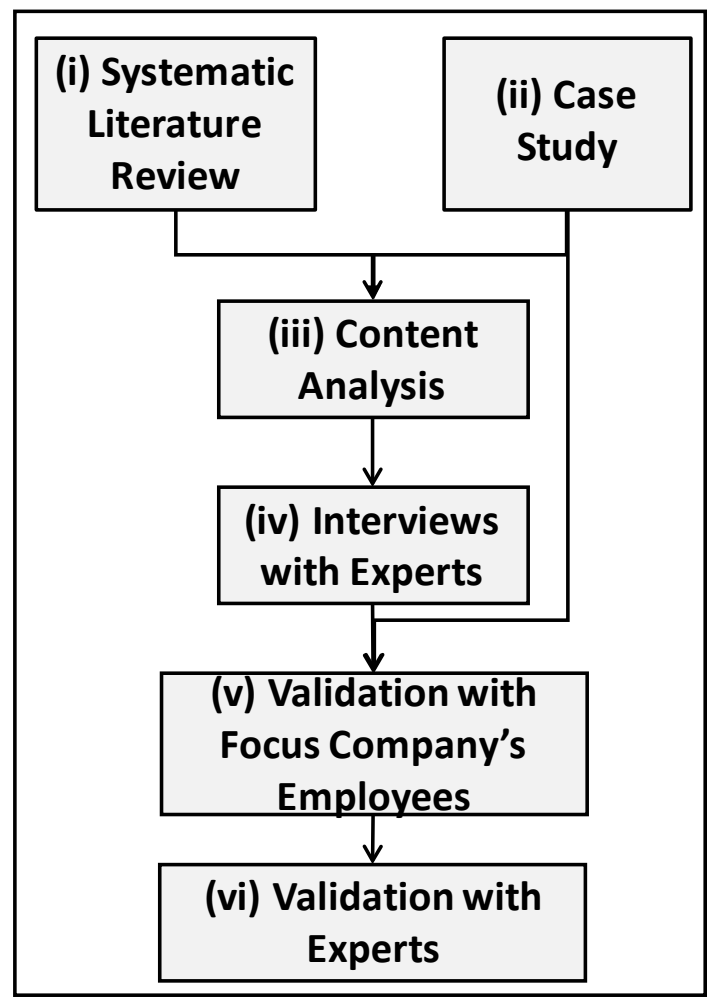

Figure 1. Combination of research methods used in this study

\section{Systematic literature review}

This study started with the conduction of a SLR using the steps proposed by Tranfield et al. (2003). Initially, a search following the protocol presented in Chart 1 resulted in 514 non-duplicated results. The research string was built by combining two groups of words. First, the word card-based itself or the name of one of the four well-known card-based system. Secondly, a word related to the practical application of those systems and empirical studies.

Chart 1. Research Protocol.

\begin{tabular}{|c|c|}
\hline & Research Protocol \\
\hline Database & Web of Science, Scopus and Engineering Village \\
\hline Publication Years & From 2009 to 2019 \\
\hline Document type & Journals and Conference Papers \\
\hline Language & English \\
\hline String & $\begin{array}{c}\text { ("kanban"OR"conwip"OR"polca"OR"cobacabana"OR"card- } \\
\text { based")AND("empirical"OR"pratical"OR"case } \\
\text { study"OR"implementation"OR"action research") }\end{array}$ \\
\hline Inclusion criteria & - Practical initiatives to implement a card-based system; \\
\hline & $\begin{array}{c}\text { At least one reference to a difficult find during the implementation } \\
\text { process or on an existing system related to human aspects. }\end{array}$ \\
\hline & - Simulation or mathematical analysis of the systems; \\
\hline
\end{tabular}


It was necessary to include conference papers, like Jungherr (2016) and Liao et al. (2017), as many empirical studies reporting card-based systems implementation are presented in this type of document.

Subsequently, two filters were applied to this database. In the first one, authors read the title and the abstract of the 514 documents to assess if they met the inclusion and exclusion criteria of the research protocol (Figure 2). The remaining 112 studies had their content fully and inclusion and exclusion criteria were applied again, resulting in 8 studies (Chart 2). The large number of exclusions in the second filter occurred because only after the full text analysis it was possible to identify whether some difficulties in implementing a card-based system were mentioned or not in the study.

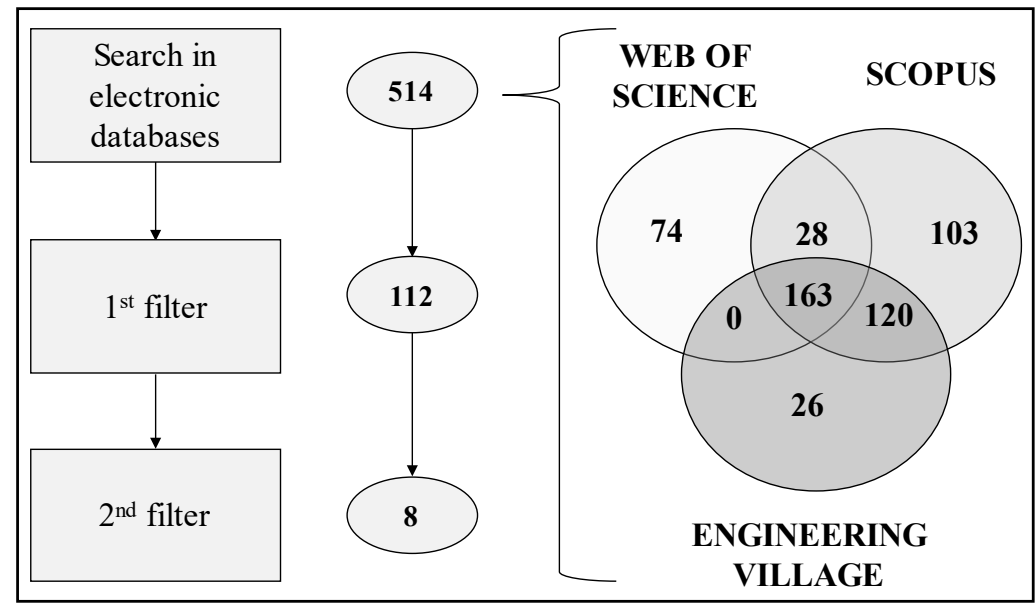

Figure 2. Filtering process results. Source: Authors

Chart 2. Systematic Literature Review Results

\begin{tabular}{|c|c|}
\hline Paper & Summary \\
\hline $\begin{array}{l}\text { Krishnamurthy and Suri } \\
\text { (2009) }\end{array}$ & $\begin{array}{l}\text { Describes the implementation of POLCA and main difficulties find } \\
\text { during the process at three different manufacturers: machine parts } \\
\text { motor control centers and aluminum extrusion. }\end{array}$ \\
\hline Slomp et al. (2009) & $\begin{array}{l}\text { Presents the implementation of CONWIP and takt time concept into a } \\
\text { strip manufacturing. A game software was developed to gain } \\
\text { acceptance of supervisors and planners in the new PCS. }\end{array}$ \\
\hline Prachař et al. (2014) & $\begin{array}{l}\text { Describes the implementation process of kanban at a manufacturing } \\
\text { company, highlighting the problems related to human factors and how } \\
\text { the company overcome them. }\end{array}$ \\
\hline Prakash et al. (2014) & $\begin{array}{c}\text { Shows how a hybrid kanban-CONWIP was implemented into a supplier } \\
\text { of a well-known aircraft, emphasizing the importance of employees } \\
\text { training. }\end{array}$ \\
\hline Crop et al. (2015) & $\begin{array}{c}\text { Describes the cultural changes necessary for CONWIP implementation } \\
\text { in a hospital, specially overcoming concern about underutilization of } \\
\text { resources. }\end{array}$ \\
\hline Papalexi et al. (2016) & $\begin{array}{l}\text { Highlights the fears of kanban implementation success in the } \\
\text { pharmaceutical sector. }\end{array}$ \\
\hline $\begin{array}{l}\text { De Vries and Van der Poll } \\
\qquad(2018)\end{array}$ & $\begin{array}{c}\text { Emphasizes the necessity of empowerment and training for operators } \\
\text { to run kanban cells in a pump-engineering organization. }\end{array}$ \\
\hline $\begin{array}{l}\text { Sánchez-Partida et al. } \\
\qquad(2018)\end{array}$ & $\begin{array}{l}\text { Presents the human difficulties to operate kanban when production } \\
\text { levels change frequently. }\end{array}$ \\
\hline
\end{tabular}

Source: Authors 
The small number of articles can be explained by two reasons. First, this is due to the fact that many articles only describe how the system works on a specific environment, giving little attention to how it was implemented. Secondly, articles tend to focus on positive aspects of the implementation, not highlighting problems that have occurred.

\section{Longitudinal case study}

An in-depth inductive case study was conducted to identify more problems and create a larger database for further analysis. The authors selected a Brazilian unit of an organization that produces a high diversity of consumer goods first because they have unrestricted access to the company and to its information databases, what make it possible to conduct a longitudinal study collecting data in multiple phases. Moreover, the unit was starting to implement kanban in the final 3 mini-factories at the beginning of data collection for this study, what was very convenient to the authors. Furthermore, as the implementation was not well succeeded, the case become more interesting, as literature usually reports only success cases. However, a failure case is more adequate to understand the difficulties face during an empirical kanban implementation.

Before the beginning of kanban project, production control was performed by an unstructured combination of the explosion of needs generated by MRP (Manufacturing Resources Planning) with manual controls on the factory floor for order prioritization. With the decision to implement kanban, a team was formed, consisting of the supervisor of Production Planning and Control, two analysts of the area and an external consultant. This team conducted the role implementation process for 8 months, when production manager decided to interrupt the project.

The motivation to start Kanban implementation was a target set by the directors to reduce stock levels. Therefore, Lean philosophy as well as other lean tool, such as 5S, kaizen, SMED (Single Minute Exchange of Dies), were not implemented in the company when Kanban project started.

The case study carried out in this paper is longitudinal as data was collected in three different stages. In the first stage, we have followed for 8 months (from February to September 2012) the entire implementation process of kanban. However, at that time it was not clear for company managers and employees the main reasons for the unsuccessful implementation. Between 2012 and 2018 (stage 2), we visited the focus company on a weekly basis. In these visits, we have collected additional information and conducted informal conversation with company's employees.

In 2018 (stage 3), six years after the company decided to interrupt the Kanban implementation, interviews with key leaders were undertaken. At this time, it was much clearer which problems were faced during the implementation process, as well as what could have been done differently.

Analysing the information collected, it was possible to identified that while in Phase 1 the reasons behind companies' failure were obvious (e.g. card were made of a non-resistant material and employees had access to print new kanban cards without any control) or generic (e.g. production do not want to collaborate with PPC and employees do not want to follow "kanban rules"), in Phases 2 and 3 the reasons become more concrete and deep (e.g. companies priorities during the implementation was other - production volume -; employees did not understand the benefits of the new system, so they were afraid it was only a mechanism to control closer their performance; employees did not want to perform complex set ups, because their performance were mainly measured regarding daily delivered volume). Therefore, much of the case study information used in the content analysis refers to data collected in Phase 2 and 3.

\section{Content analysis}

In step (iii), a content analysis in 8 articles selected and the case study information was conduct in order to identify soft factors critical to a successful implementation of card-based 
systems. An exploratory approach was used, as codes were not clear before the analysis of the material. It is worth mentioning that a computer-assisted text analysis software was used, named QDA Miner 5.

To code the material, we defined a procedure based on Haapanen and Tapio (2016) and Friel and Pinot de Villechenon (2018). We evaluated if sentences presented problems to implement a card-based system that were related to soft factors influence. If so, we tried to summarize the content without losing meaning (meaning units). Second, we grouped terms into 14 groups, associating each one of them to a factor. During this process, we had to condense and synthetize texts to identify the core content. This activity was especially difficult because soft factors nomenclature varies greatly among the authors. Moreover, some difficulties could be related to different factors. However, we tried to focus on the most relevant ones.

\section{Interviews with experts}

In step (iv), interviews with six experts were conducted to refine the initial proposal and to increase research validity (Shrouf and Miragliotta, 2015). Experts were carefully selected, coming from three different areas: academia, industry and consultancy (Chart 3).

Chart 3. Experts' characteristics

\begin{tabular}{|c|c|}
\hline Expert & Brief description \\
\hline Expert 1 & $\begin{array}{l}\text { University professor who has been researching in the PPC area for more than } 20 \text { years } \\
\text { and has published more than } 30 \text { papers in important journals, many of them about } \\
\text { PCS. }\end{array}$ \\
\hline Expert 2 & $\begin{array}{l}\text { University professor who has been researching in the PPC area for more than } 10 \text { years, } \\
\text { with particular attention to kanban variations and its implementation in real cases. }\end{array}$ \\
\hline Expert 3 & $\begin{array}{l}\text { Consultant of PPC with more than } 30 \text { years of experience. He has led kanban and } \\
\text { CONWIP implementation projects in more than } 10 \text { different organizations. }\end{array}$ \\
\hline Expert 4 & Consultant with more than 20 years of experience and a PhD in organizational culture. \\
\hline Expert 5 & $\begin{array}{l}\text { Production planner in a transnational company and has been part of three kanban } \\
\text { implementation projects. }\end{array}$ \\
\hline Expert 6 & $\begin{array}{l}\text { Production supervisor in a large transnational manufacturer and has more } 20 \text { years of } \\
\text { experience in his position. }\end{array}$ \\
\hline
\end{tabular}

Source: Authors

The interviews procedure was based on Silveira et al. (2017). We sent each expert list of the factors, their definitions and pieces of evidences founded in the SLR and in the LCS. For each factor, we asked:

- Do you agree this is a critical soft factor for card-based systems implementation? If not justify.

- Do you agree with its name? If not, what would be a better name?

- Do you agree with its description? If not, what would be a better description?

Then, we also asked a more general question to assess model completeness:

- Do you think any soft factor are missing? If so, what it would be? Give an example of it.

Their answers were categorized into: no change $(\mathrm{N})$, refinement in semantics and syntax (R) and change in the factor focus (C). Each expert did not have access to other experts' answers. Seeking results convergence, if three or more experts recommend a refinement or change, the authors evaluate their justifications and conduct changes in the factor. 


\section{Validation with company's employees}

In step (v), authors returned to LCS company to present the factors list and evaluate if the there was it misses any important information. Three of the company's leaders, who were part of the six employees interviewed in phase 3 of the case study, participated in the session. The authors presented the final proposal for 25 minutes and the employees discussed among themselves for 105 minutes if the understand the list should be modified in some way, but they did not recommend any change and approved the list of factors and their definitions.

\section{Validation with experts}

Finally, we returned to the six experts' interviews individually to presented the final results also looking for any missing information. The procedure was similar to the one conducted with company's employees. Some minor issues were raised and discussed, but the experts agreed the list represented all the factors the understand were important to a cardbased system implementation.

\section{Research quality}

According to Yin (2014), four tests are commonly used to determine the quality of an empirical research. In this research, construct validity is evidenced through the use of multiple sources of evidence and the review of the data obtained by the interviewees, including a final validation with company's employees.

Regarding internal validity, success stories from literature were compared with a case in which the company failed to implement a card-based system, aiming to understand the intensity each soft factor was practiced in each situation.

External validity refers to the potential for generalization of findings to other situations. In this research, only a single case was conducted. However, other cases of literature were also used in the analysis (SLR) and the soft factors proposed after the content analysis were review by 6 experts.

Reliability is based on the research protocols for each research method used in this research, which were described in detail through section 2, including how data were collected. Also, it was specified in which order research methods were conducted (Figure 1).

\section{Initial list of soft factors}

After the content analysis, 14 soft factors were identified. Below, each of them are presented in detail.

\section{Cultural change}

To implement a card-based system, an organization needs to shift some of its paradigms. For example, it may be necessary to reduce the level of centralization of PPC and to change focus from equipment's utilization to work in process level. In CONWIP, for example, if the PCS works correctly, a machine would not work $100 \%$ of the time. However, in a case presented by Crop et al. (2015) employees were concerned about the underutilization of the machine and violation of CONWIP rules, producing without necessity (an available container and card). This attitude broke the entire logic of the system and prevented the company to achieve the expected results of CONWIP.

In the LCS, we also noticed resistance to PCS implementation. Production supervisors resisted to not controlling the scheduling of their production lines, as they understood this decision as a way to reduce their autonomy in the company and increase the importance of PPC department. Therefore, they manipulated cards, not respecting kanban priorities. 


\section{Clear motivation to implement a card-based system}

The reasons and the expected benefits of implementing a card-based system should be clear to all employees so that they know why company decided to implement that system. Krishnamurthy and Suri (2009) presented a case in which a company (AEC) knew its objectives in implementing POLCA. This, however, was not observed in the LCS. The project team has reported that employees understood kanban tasks only as a way for managers to control their performance. Therefore, the project team struggled to accomplish the kanban implementation.

\section{Management support}

Managers should support the project team during the project, reinforcing their leadership. This was a big issue in the LCS, as PPC was just started as a formal department in the studied company. Manager support was insufficient, and the project team was not listened by production supervisors.

\section{Implementation during low demand period}

Implementing a new tool is a risk for a company. In order to mitigate this risk, it is interesting to implement a card-based system during a low demand period, when eventual failures can be correct without affecting service level. This was done in the case presented by Prakash et al. (2014), but not in the LCS, since kanban was implemented in a period in which production supervisors were focused on delivering higher production volume. Therefore, the first difficulties faced during the implementation discouraged employees to implement kanban.

\section{Conducting a pilot project}

Conducting a pilot project is a way to reduce risks and to gain confidence in the new system. Therefore, it is interesting to first implement a card-based system in a small portion of the shop floor. Krishnamurthy and Suri (2009) and Papalexi et al. (2016) reported an increase in employee's enthusiasm and confidence in the system (POLCA and kanban, respectively) after it was implemented as a pilot. On the other hand, in the LCS, kanban was implemented in all 3 production lines during the same time, involving more than 100 machines. Therefore, difficulties and distrust in kanban increased up to the point that the manager decided to quit the implementation.

\section{Computer and physical simulation}

Another way to gain confidence in the system is through computational (Slomp et al., 2009) or physical (Prakash et al., 2014) simulation. Therefore, employees and managers could literally see how it would work, mitigating many of their doubts. No simulation of kanban was conducted in the LCS.

\section{Employees training}

Training is an essential step in a card-based systems implementation so that employees understand the principles and rules, as reported by Krishnamurthy and Suri (2009) and Prachař et al. (2014). In the LCS, training was very fast and superficial, raising doubts about how the system would work in practice. For example, employees returned a card from production line 3 to production line 1 before the reorder point because they were afraid of lacking material. 


\section{Employees empowerment}

Managers should give employees autonomy to make decisions on the shop floor consistent with the card-based system being implemented. While De Vries and van der Poll (2018) report self-directed employees managing kanban systems, employees from the LCS said they felt managers did not trust them, because every day someone went to the shop floor to see if they were doing the tasks correctly.

\section{Employees discipline}

Employees should follow the systems procedures, regardless the difficulties it may bring. For example, in the LCS as well as in Slomp et al. (2009), it was observed difficulties in making employees follow cards priorities when they had to make complex setups or orders. Moreover, in the LCS, it was observed that employees resisted to send each card to production line 1 as soon as they reached the reorder point. Instead, they waited until they accumulated some cards to spend less time walking in the factory. With this attitude, while in some moments there were almost no cards in the board, suddenly there were many in the red zone, breaking kanban priorities' mechanism.

\section{Employees involvement}

Employees should be part of the implementation team and should be involved in decision-making since the beginning of the implementation process. Papalexi et al. (2016) reinforced the importance of all stakeholders being involved in the implementation, while De Vries and van der Poll (2018) highlighted the role of a teamwork and participation of all relevant departments in the implementation team. In the LCS, on the other hand, we observed that production members were not involved in the beginning in the project. Moreover, according to a production leader "the project had several problems and, when implementation started, we (shop floor employees) said it would not work, but nobody listened to our opinion".

Control the number of cards on the shop floor

Considering cards were correctly sized, it is important to control if they were not lost in production as they could result in a lack of material. Therefore, Prachař et al. (2014) suggested conducting regular inventory audits. In the LCS, much evidence related to this factor was observed. First, in more than one occasion we noticed employees taking kanban card home in their pocket by mistake. Therefore, the system would work with at least one production shift with one less card for a given product. Moreover, there were also problems related to excess of cards, as shop floor employees had access to kanban card files. This permission was given with the aim that they could reprint some damaged card. However, it was used to control the number of cards of each product in the factory, which results in no control to PPC. Finally, shop floor employees made it difficult to PPC control kanban cards because they were afraid of losing their job. Therefore, they have hidden cards as PPC was not able to perform card inventories.

\section{Card's material quality}

Cards must be made of resistant materials, such as laminated cards (Krishnamurthy and Suri, 2009). Otherwise, they could be damaged and lost in production. This was observed in the LCS, as stocks hooks rip kanban cards. 


\section{Card's information quality}

The cards must contain all the necessary information, but, at the same time, they should be as simple and visual as possible. Lack of information or difficulty to understand can make employees not follow the system or reduce their confidence on it. This was a positive point in the LCS, as cards layout, even though company did not use kanban system anymore, were still used in production. Moreover, employees also agreed that the layout was very good.

\section{Physical adaptations in the factory}

Changes in the shop floor may be necessary to facilitate card-based systems operation (e.g. layout changes and purchase of boards and containers). In the LCS, it was observed that containers size was not adequate to kanban cards quantity. Therefore, more material was delivered than the requested amount. Moreover, employees needed to walk on one side of the shelves to check if the stock was empty and then walk on the other side to remove the necessary cards.

\section{Refined list of soft factors}

The refined list after step (vi) is presented in Chart 4. From the initial list, some modification occurred in five factors, either in the name or in the definition. Moreover, another factor was included in the list "Clear definition of responsibilities".

Regarding the changes performed, "Cultural change" became "Paradigm change". Four experts recommended some modification in the name of this factor and one of them argued that the factor did not represent the whole organizational cultural dimension. Moreover, we also decided to soften part of description replacing "to break some of its paradigms" by "to be able to rethink some of its paradigms". In the second factor, it was highlighted that it should not only be clear what the organization goals are but also the expected benefits from achieving these goals, as the benefits can also be a source of motivation for a company to implement a card-based system.

In the third factor, name and definition were modified to emphasize that top management support is essential to successfully implement it throughout the company. Moreover, four of the six experts recommended excluding the statement "giving them autonomy to make decisions", because they understood this was part of another factor (i.e. employees empowerment). Following their recommendation, we eliminated this statement of the factor definition.

Regarding the fifth factor (Conduction a pilot project), the following phrase was added in the definition: "The pilot project also allows an apprenticeship that can be used to continue the deployment in the rest". This phrase was suggested by one of the experts and reinforced the factor objective of gaining experience and practical knowledge from implementing a cardbased system in each part of the shop floor.

Finally, modifications occurred in the ninth factor (Employees discipline). First, commitment was added together with discipline in the factor name. Because employees should not only respect the rules, but also understand why they need to follow them in order to the system work as planned.

Moreover, an additional factor was included in the soft factors list. This factor was recommended by three experts who argued that each member of the project or sponsor needed to know what their responsibilities are, as well as the responsibilities from other members. In turn, for each new task the project team would have to discuss who would perform it. This occurred in the organization of the LCS, as it was not clear which tasks were under the responsibility of the production department and which were from PPC. Therefore, some tasks were not performed while others received attention. 
Chart 4. Soft factors list refined by experts

\begin{tabular}{|c|c|c|}
\hline $\mathbf{N}$ & Soft Factor & Definition \\
\hline 1 & Paradigm change & $\begin{array}{l}\text { The organization needs to be able to rethink some of its paradigms to } \\
\text { implement a card-based system (e.g.it may be necessary to change } \\
\text { focus on equipaments utilization and to reduce PPC centralization). }\end{array}$ \\
\hline 2 & $\begin{array}{l}\text { Clear motivation and } \\
\text { implement a card- } \\
\text { based system }\end{array}$ & $\begin{array}{l}\text { It should be clear to managers and employees what goals the } \\
\text { organization seeks to achieve with the implementation of a specific } \\
\text { card-based system, as well as the expected benefits. }\end{array}$ \\
\hline 3 & $\begin{array}{l}\text { Top management } \\
\text { support }\end{array}$ & $\begin{array}{l}\text { Managers and executives must support the project team, giving them } \\
\text { autonomy to make decisions. }\end{array}$ \\
\hline 4 & $\begin{array}{l}\text { Implementation } \\
\text { during low demand } \\
\text { period }\end{array}$ & $\begin{array}{l}\text { During a low demand period, failures in the system can be corrected } \\
\text { without affecting service level. }\end{array}$ \\
\hline 5 & $\begin{array}{l}\text { Conducting a pilot } \\
\text { project }\end{array}$ & $\begin{array}{l}\text { Implementing the selected card-based system in only a small portion } \\
\text { of the shop floor is essential for employees and managers to gain } \\
\text { confidence in the system. The pilot project also allows an } \\
\text { apprenticeship that can be used to continue the deployment in the rest } \\
\text { of the operation }\end{array}$ \\
\hline 6 & $\begin{array}{l}\text { Computer and } \\
\text { physical simulation }\end{array}$ & $\begin{array}{l}\text { Simulation is a cheap way to test a system under specific conditions on } \\
\text { the shop floor, bringing confidence to managers and employees. }\end{array}$ \\
\hline 7 & Employees training & $\begin{array}{l}\text { Training of employees is essential so that they understand principles } \\
\text { and rules of the card-based system being implementated. }\end{array}$ \\
\hline 8 & $\begin{array}{l}\text { Employees } \\
\text { empowerment }\end{array}$ & $\begin{array}{l}\text { Employees must have autonomy to make decisions on the shop floor } \\
\text { consistent with the card-baserd system being implemented. }\end{array}$ \\
\hline 9 & $\begin{array}{l}\text { Employees discipline } \\
\text { and commitment }\end{array}$ & $\begin{array}{l}\text { Employees must follow all the rules of the implemented card-based } \\
\text { system regardless of the difficulties these rules may bring, such as } \\
\text { complex set ups. }\end{array}$ \\
\hline 10 & $\begin{array}{l}\text { Employees } \\
\text { involvement }\end{array}$ & $\begin{array}{l}\text { Employees should be part of the implementation team and should be } \\
\text { involved in decision-making since the beginning of the implementation } \\
\text { process. }\end{array}$ \\
\hline 11 & $\begin{array}{l}\text { Control the number of } \\
\text { cards on the shop } \\
\text { floor }\end{array}$ & $\begin{array}{l}\text { Considering an adequate number of cards where size, is important to } \\
\text { control those cards in the shop floor in order to reprint lost cards as } \\
\text { well as to remove cards when necessary. }\end{array}$ \\
\hline 12 & Cards' material quality & Cards must be made of resistant materials. \\
\hline 13 & $\begin{array}{l}\text { Cards' information } \\
\text { quality }\end{array}$ & $\begin{array}{l}\text { Cards must transmit all the necessary information to employees being } \\
\text { as simple and visual as possible. }\end{array}$ \\
\hline 14 & $\begin{array}{l}\text { Physical adaptations } \\
\text { in the factory }\end{array}$ & $\begin{array}{l}\text { Changes in the shop floor may be necessary to facilitate card-based } \\
\text { system operation (e.g. layout changes and purchase of boards and } \\
\text { containers). }\end{array}$ \\
\hline 15 & $\begin{array}{l}\text { Clear definition of } \\
\text { responsabilities }\end{array}$ & $\begin{array}{l}\text { Each member of the project or sponsor need to know what their } \\
\text { responsibilities are, as well as the responsibilities of the other } \\
\text { members. }\end{array}$ \\
\hline
\end{tabular}

Source: Authors

\section{DISCUSSION}

The proposed factors can be divided into two large groups. The first one contains classic management factors that can be applied in many contexts (Chart 5). A second group includes factories more specific to a production environment (factors 4, 5, 6 and 14). However, those factories can be used in other environments with small adaptations. Finally, a third group includes three factors specifically relevant to the implementation of card-based systems. They involve unique features of card-based systems, in particular card-related elements (factors 11, 12 and 13). 
Chart 5. Classic management soft factors

\begin{tabular}{|c|c|}
\hline Soft Factors & Some literature references \\
\hline Paradigm change & $\begin{array}{c}\text { Marodin and Saurin (2013), Hu et al. (2015), Netland (2016) } \\
\text { and Sony and Naik (2020) }\end{array}$ \\
\hline $\begin{array}{l}\text { Clear motivation and implement a } \\
\text { card-based system }\end{array}$ & $\begin{array}{l}\text { Marodin and Saurin (2013), Netland (2016), Alhuraish et al. } \\
\text { (2017), Gunduz and Yahya (2018), Knol et al. (2018) and Sony } \\
\text { and Naik (2020) }\end{array}$ \\
\hline Top management support & $\begin{array}{l}\text { Pons (2010), Marodin and Saurin (2013), Hu et al. (2015), } \\
\text { Netland (2016), Alhuraish et al. (2017), Gunduz and Yahya } \\
\text { (2018) and Sony and Naik (2020) }\end{array}$ \\
\hline Employees training & $\begin{array}{c}\text { Marodin and Saurin (2013), Hu et al. (2015), Netland (2016), } \\
\text { Alhuraish et al. (2017) and Knol et al. (2018) }\end{array}$ \\
\hline Employees empowerment & Alhuraish et al. (2017) and Sony and Naik (2020) \\
\hline $\begin{array}{l}\text { Employees discipline and } \\
\text { commitment }\end{array}$ & $\begin{array}{l}\text { Alhuraish et al. (2017), Gunduz and Yahya (2018) and Sony and } \\
\qquad \text { Naik (2020) }\end{array}$ \\
\hline Employees involvement & $\begin{array}{l}\text { Pons (2010), Marodin and Saurin (2013), Netland (2016), } \\
\text { Alhuraish, Robledo and Kobi (2017) and Knol et al. (2018) }\end{array}$ \\
\hline Clear definition of responsabilities & $\begin{array}{l}\text { Marodin and Saurin (2013), Netland (2016) and Knol et al. } \\
\text { (2018) }\end{array}$ \\
\hline
\end{tabular}

Source: Authors

Among the proposed factors, three of them were found only in the LCS; i.e. no empirical literature evidence referred this factor. The first is factor 3 (top management support), which was possible to identify because, throughout the seven years of data collection, the researcher became really closed to company's employees.

The second factor, card's information quality (factor 13), although not identified in the selected studies, presents vast material in the literature (e.g. Suri, 1998; Lage Junior and Godinho Filho, 2010; Serrato, 2016). Therefore, it does not present a different result from literature.

Finally, factor 14 (physical adaptations in the factory) presents physical difficulties for the system to function as intended. The fact that SLR studies did not present this factor could be associated with its direct relation to the implementation project team. Therefore, it may be easier to attribute difficulties to more generic groups, such as the entire organizations (e.g. factors 1, 2 and 3) or employees (e.g. factors 7, 8, 9 and 10) than to a specific group involved in the project.

Factor 15 (clear definition of responsibilities) included by experts is also a classic management factor. Its addition reinforces the implementation project planning, given the high complexity and the need for task division. This factor was observed in both the SLR and LCS, but when performing the content analysis, it was already encompassed by factor 3 (top management supported). After the experts' opinion, this factor was included as a new one.

\section{Propositions}

Given the LCS observations, the resultant list of soft factors and the discussions previously presented, three propositions are formulated.

P1: Card-based systems are largely influenced by humans so that soft factors are critical to a successful implementation of those systems.

Many tasks in a card-based system are performed by shop floor employees, such as moving cards from one place to the other when a certain situation occurs (e.g. reorder pointing) and starting production only when some conditions occur (e.g. there is an available container and an available card) (Spearman et al., 1990; Suri, 1998; Thürer et al., 2014). This situation is different from computerized systems, such as MRP, in which most of the tasks are centralized and performed by computer algorithms. Therefore, it can be argued that there is 
a great human influence on card-based systems and understanding how to motivate and engage employees (soft factors) are critical to successfully implementing those systems (Salem et al., 2006; Liu and Huang, 2009).

In the LCS, it was observed that employees were afraid of kanban implementation, as they understood it only as a way for managers controlling their performance. Therefore, they resisted to its implementation. Another example, also observed in the LCS, was that employees mistakenly took kanban cards in their pocket. These affected the system as the number of cards of a given item was a fundamental parameter for kanban operation. Therefore, controlling the number of cards and employees' discipline are fundamental factors for kanban successful implementation.

P2: Soft factors for card-based systems implementation involve classic management factors and specific factors (e.g. card's information quality).

Many studies proposed soft factors for the implementation of a given tool. Some of those factors are generic and could be applied to basic tools, such as management support, employee's involvement and communication (Hu et al., 2015; Netland, 2016; Azyan et al., 2017; Knol et al., 2018). However, there were also specific factors, which have been rarely studied in the context of card-based systems (Pons, 2010). Therefore, three specific factors are proposed: control the number of cards on the shop floor, card's material quality and card's information quality. Although not sophisticated, these factors can have a great negative impact on a card-based systems operation.

Card's material quality is important because it reduces the probability of card's damage and lost, helping in the control of the number of cards in the shop floor. Second, it raises the importance of the system on the shop floor, indicating that the system will be operating for a long time as cards are not temporary.

Moreover, card's information quality, containing all the information in a simple way, is essential to employees' involvement in the system, as they need to understand the system (and specially the cards) to perform their tasks correctly.

P3: Soft factors for card-based systems implementation involve factors at the organization level, at the implementation group level and at the individual level.

Following Blakeney (1983) analysis of organizational behaviour, the factors proposed can be classified into three groups. The first one includes factors that involve the whole organization. For example, paradigms change and clear motivation to implement a card-based system (factors 1 and 2). Moreover, all employees needed to trust in the system under implementation. Thus, factors 4 and 5 were also part of this group. Furthermore, employees that were not involved in the project would primarily evaluate its physical parts. We also included factors 11, 12, 13 and 14 in the organization level.

The second level is the implementation group, which includes all employees involved during the planning and execution of the project. For this group, the support of top management is essential (factors 3 ), so that they will have the necessary resources to the project as well as the importance of the project would be highlighted to the entire organization. Simulation of the system is also important to refine concepts and test alternative solutions (factor 6). Note that we considered this factor at the group level as its primary objective was not to gain confidence in the system as factor 5 , but to understand and adapt it to the organization's contextual factors. Empowerment (factor 8 ) is essential for speeding decision-making and for formalizing group authority in the project. Involving employees in the project group removes barriers and resistance to the project and the changes necessary to be made in the organization. In addition, factor 15 (to clearly define the responsibilities during the implementation) is also at this level.

The third level involves factors that are important at the individual level. Individuals are the ones who participated in the implementation project. They need initial training (factor 7) to understand the system and what needed to be done to implement it. Second, employees' discipline and commitment to the project was essential for its success. 


\section{Card-based soft factors house}

Following propositions 2 and 3, we framed these factors in categories (see Figure 3). As "houses" are used in the literature for many different topics (e.g. Lean house), we proposed a card-based system's soft factors house. Hard factors are the basis of our house, because without the necessary investment and resources (in general), soft factors will not be sufficient for successful implementation (Pons, 2010).

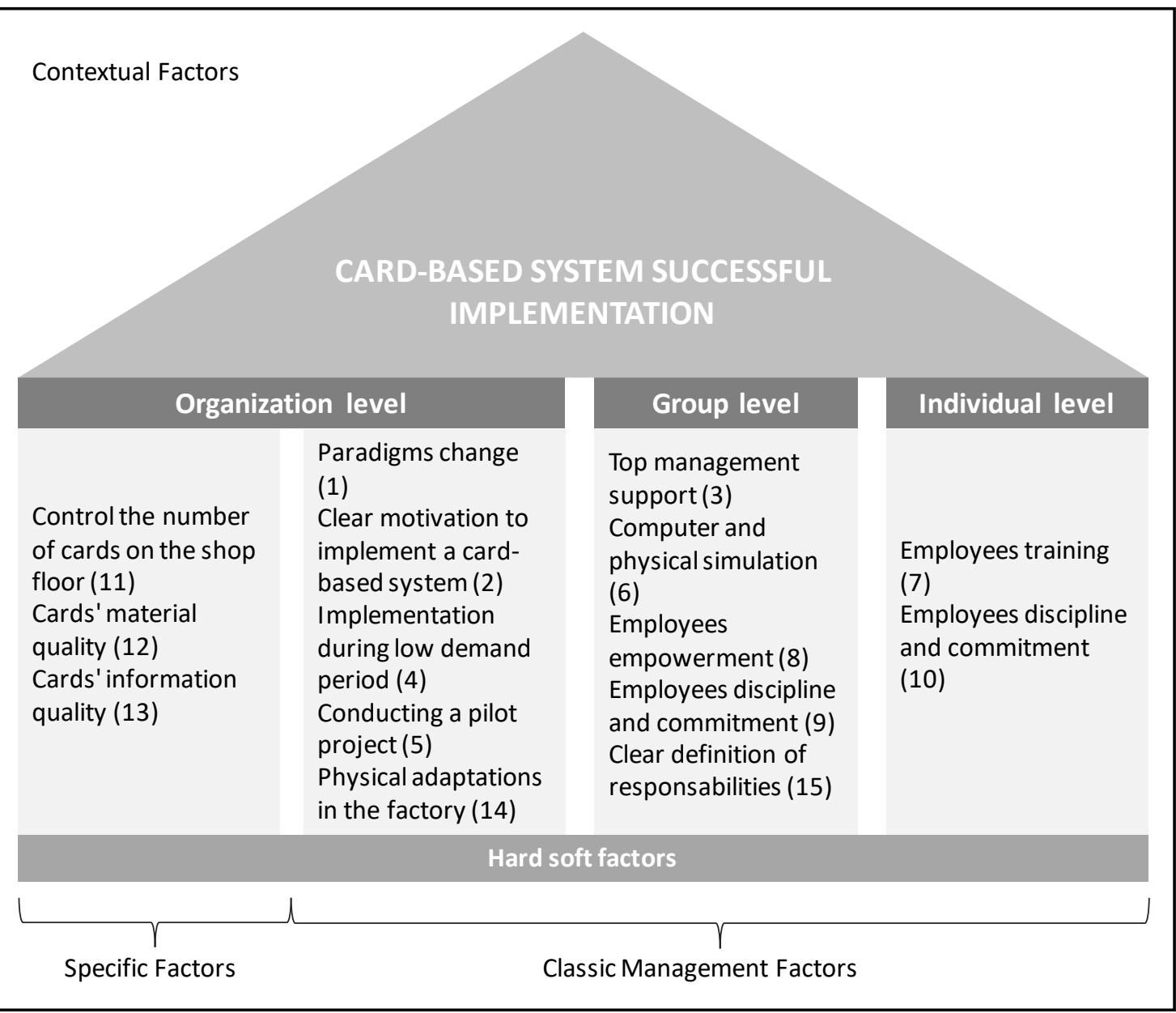

Figure 3. Categorization of soft factors related to card-based systems implementation. Source: Authors

The house has four pillars. The first one involves factors specific to card-based systems. All those factors are classified in the organization level. The other factors are placed on their level (organizational, group and individual) as explained in proposition 3.

The house is surrounded by contextual factors, which need to be understood to adapt the system and the way it will be implemented to meet the specific characteristics of the organization.

\section{CONCLUSIONS AND RESEARCH AGENDA}

Since there is a strong human influence on card-based systems, understanding which soft factors are critical to the success in implementing those systems is essential. The 15 factors proposed are generic, so additional factors can be included due to contextual variables and conditions specific to the environment studied.

For literature, this paper contributes by highlighting the importance of human factors in the implementation of card-based systems, by identified specific soft factors critical to cardbased systems implementation and by presenting a case of failure in the implementation of kanban, something unique given that most studies report only success stories. 
For practice, the proposed list aims to increase empirical success in the implementation of card-based system. Therefore, a larger number of empirical works on this subject is expected, given the reduced number of articles reporting empirical cases of PCS's, especially the most recent ones.

A limitation of our study is that only a single case was conducted. However, due to the long-time of data collection (7 years), it was not feasible to conduct more than one case with the same depth. Moreover, the scarce literature about PCS's soft factors did not provide substantial elements to compare or discuss the findings of these articles. Therefore, we expect future studies enhance this paper analyzing and refining our proposed list in different cardbased production environments. Others potential research questions are proposed in Chart 6 .

Chart 6. Research Agenda

\begin{tabular}{|c|c|c|}
\hline Subject & Motivation & Potential research questions \\
\hline \multirow{2}{*}{$\begin{array}{l}\text { Relative } \\
\text { importance of } \\
\text { each factor }\end{array}$} & \multirow{2}{*}{$\begin{array}{l}\text { Some of the factors presented may } \\
\text { have great influence on a } \\
\text { successful implementation of a } \\
\text { card-based system them others. }\end{array}$} & $\begin{array}{l}\text { What is the relative importance of each } \\
\text { card-based system implementation soft } \\
\text { factors? }\end{array}$ \\
\hline & & $\begin{array}{l}\text { How do factors interact among } \\
\text { themselves? }\end{array}$ \\
\hline $\begin{array}{l}\text { Card-based } \\
\text { systems and soft } \\
\text { factors }\end{array}$ & $\begin{array}{l}\text { Each card-based system has its } \\
\text { characteristics and mode of } \\
\text { operation, requiring different levels } \\
\text { of human influence and expertise } \\
\text { of the shop floor employees. }\end{array}$ & $\begin{array}{l}\text { Which soft factors are more important to } \\
\text { each card-based system (e.g. Kanban, } \\
\text { CONWIP, POLCA, COBACABANA)? }\end{array}$ \\
\hline $\begin{array}{l}\text { Contextual } \\
\text { variables }\end{array}$ & $\begin{array}{c}\text { Characteristics of the environment } \\
\text { can influence the implementation } \\
\text { of a system and therefore the list } \\
\text { of soft factors. }\end{array}$ & $\begin{array}{l}\text { How contextual variables, such as } \\
\text { Demand response strategy, Geographic } \\
\text { location, Employees expertise, among } \\
\text { other, affect the card-based system } \\
\text { implementation soft factors? }\end{array}$ \\
\hline $\begin{array}{l}\text { Organizational } \\
\text { culture }\end{array}$ & $\begin{array}{l}\text { The organization' culture can } \\
\text { create barriers or boost the } \\
\text { implementation of changes, such } \\
\text { as a card-based system. }\end{array}$ & $\begin{array}{l}\text { How can organization culture be modified } \\
\text { in order to increase the success in } \\
\text { implementing a card-based system? }\end{array}$ \\
\hline
\end{tabular}

Source: Authors

\section{REFERENCES}

Alhuraish, I., Robledo, C. and Kobi, A. (2017), "A comparative exploration of lean manufacturing and six sigma in terms of their critical success factors", Journal of Cleaner Production, Vol. 164, pp. 325-37.

Azyan, Z.H.A., Pulakanam, V. and Pons, D. (2017), "Success factors and barriers to implementing lean in the printing industry: a case study and theoretical framework", Journal of Manufacturing Technology Management, Vol. 28, No. 4, pp. 458-84.

Bagni, G., Godinho Filho, M., Thürer, M. et al. (2020), "Systematic review and discussion of production control systems that emerged between 1999 and 2018", Production Planning and Control. In press.

Blakeney, R. (1983), "The organizational, group and individual levels of analysis in organizational behavior", Transactional Analysis Journal, Vol. 13, No. 1, pp. 58-64.

Crop, F., Lacornerie, T., Mirabel, X. et al. (2015), "Workflow optimization for robotic stereotactic radiotherapy treatments: application of constant work in progress workflow", Operations Research for Health Care, Vol. 6, pp. 18-22.

De Vries, H. and Van Der Poll, H.M. (2018), "Cellular and organisational team formations for effective LEAN transformations", Production \& Manufacturing Research, Vol. 6, No. 1, pp. 284-307.

Friel, D. and Pinot de Villechenon, F. (2018), "Adapting a Lean Production Program to National Institutions in Latin America: Danone in Argentina and Brazil", Journal of International Management, Vol. 24, No. 3, pp. 284-99. 
Gunduz, M. and Yahya, A.M.A. (2018), "Analysis of project success factors in construction industry", Technological and Economic Development of Economy, Vol. 24, No. 1, pp. 67-80.

Haapanen, L. and Tapio, P. (2016), "Economic growth as phenomenon, institution and ideology: a qualitative content analysis of the 21 st century growth critique", Journal of Cleaner Production, Vol. 112, pp. 3492-503.

Hendrick, H.W. and Kleiner, B.M. (2001), Macroergonomics: An Introduction to Work System Design, Human Factors and Ergonomics Society, Santa Monica.

Hendry, L., Huang, Y. and Stevenson, M. (2013), "Workload control: successful implementation taking a contingency-based view of production planning and control", International Journal of Operations \& Production Management, Vol. 33, No. 1, pp. 69-103.

Hu, Q., Mason, R., Williams, S.J. et al. (2015), "Lean implementation within SMEs: a literature review", Journal of Manufacturing Technology Management, Vol. 26, No. 7, pp. 980-1012.

Jungherr, A. (2016), "Twitter use in election campaigns: a systematic literature review", Journal of Information Technology \& Politics, Vol. 13, No. 1, pp. 72-91.

Karrer, C., Alicke, K. and Günther, H.-O. (2012), "A framework to engineer production control strategies and its application in electronics manufacturing", International Journal of Production Research, Vol. 50, No. 22, pp. 6595-611.

Knol, W.H., Slomp, J., Schouteten, R.L.J. et al. (2018), "Implementing lean practices in manufacturing SMEs: testing 'critical success factors' using Necessary Condition Analysis", International Journal of Production Research, Vol. 56, No. 11, pp. 3955-73.

Krishnamurthy, A. and Suri, R. (2009), "Planning and implementing POLCA: a card-based control system for high variety or custom engineered products", Production Planning and Control, Vol. 20, No. 7, pp. 596-610.

Lage Junior, M. and Godinho Filho, M. (2010), "Variations of the Kanban System: literature review and classification", International Journal of Production Economics, Vol. 125, No. 1, pp. 13-21.

Liao, Y., Deschamps, F., Loures, E.F.R. et al. (2017), "Past, present and future of Industry 4.0: a systematic literature review and research agenda proposal", International Journal of Production Research, Vol. 55, No. 12, pp. 3609-29.

Liberopoulos, G. and Dallery, Y. (2000), "A unified framework for pull control mechanisms in multi-stage manufacturing systems", Annals of Operations Research, Vol. 93, No. 1/4, pp. 325-55.

Liu, Q. and Huang, D. (2009), "Dynamic card number adjusting strategy in card-based production system", International Journal of Production Research, Vol. 47, No. 21, pp. 6037-50.

Marodin, G.A. and Saurin, T.A. (2013), "Implementing lean production systems: research areas and opportunities for future studies", International Journal of Production Research, Vol. 51, No. 22, pp. 6663-80.

Netland, T.H. (2016), "Critical success factor for implementing lean production: the effect of contingencies", International Journal of Production Research, Vol. 54, No. 8, pp. 2433-48.

Papalexi, M., Bamford, D. and Dehe, B. (2016), "A case study of kanban implementation within the pharmaceutical supply chain", International Journal of Logistics Research and Applications, Vol. 19, No. 4, pp. 239-55.

Pons, D. (2010), "System model of production inventory control", International Journal of Manufacturing Technology and Management, Vol. 20, No. 1, pp. 120-55.

Prachař, J., Fidlerová, H., Sakál, P. et al. (2014), "Improving the sustainability and effectiveness of the inventory management in manufacturing company", Applied Mechanics and Materials, Vol. 693, pp. 141-6.

Prakash, J., Chin, J.F. and Zhou, Z. (2014), "Implementation of hybrid parallel kanban-CONWIP system: a case study", Cogent Engineering, Vol. 1, No. 1, 938922.

Salem, O., Solomon, J., Genaidy, A. et al. (2006), "Lean construction: from theory to implementation", Journal of Management Engineering, Vol. 22, No. 4, pp. 168-75.

Sánchez-Partida, D., Rodríguez-Méndez, R., Martínez-Flores, J.L. et al. (2018), "Implementation of continuous flow in the cabinet process at the Schneider Electric Plant in Tlaxcala, Mexico", INFORMS Journal of Applied Analytics, Vol. 48, No. 6, pp. 566-77. 
Serrato, R.B. (2016), "REDUTEX: a hybrid push-pull production system approach for reliable delivery time in knitting SMEs", Production Planning and Control, Vol. 27, No. 4, pp. 263-79.

Shrouf, F. and Miragliotta, G. (2015), "Energy management based on Internet of Things: practices and framework for adoption in production management", Journal of Cleaner Production, Vol. 100, pp. 23546.

Silveira, W.G., Lima, E.P., Costa, S.E.G. et al. (2017), "Guidelines for Hoshin Kanri implementation: development and discussion", Production Planning and Control, Vol. 28, No. 10, pp. 843-59.

Slomp, J., Bokhorst, J.A.C. and Germs, R. (2009), "A lean production control system for high-variety/lowvolume environments: a case study implementation", Production Planning and Control, Vol. 20, No. 7, pp. 586-95.

Sony, M. and Naik, S. (2020), "Critical factors for the successful implementation of Industry 4.0: a review and future research direction", Production Planning and Control, Vol. 31, No. 10, pp. 799-815.

Spearman, M.L., Woodruff, D.L. and Hopp, W.J. (1990), "CONWIP: a pull alternative to Kanban", International Journal of Production Research, Vol. 28, No. 5, pp. 879-94.

Suri, R. (1998), Quick Response Manufacturing, Productivity Press, Portland.

Thürer, M., Land, M.J. and Stevenson, M. (2014), "Card-based workload control for job shops: Improving COBACABANA", International Journal of Production Economics, Vol. 147, pp. 180-8.

Tranfield, D., Denyer, D. and Smart, P. (2003), "Towards a methodology for developing evidence-informed management knowledge by means of systematic review", British Journal of Management, Vol. 14, No. 3, pp. 207-22.

Yin, R.K. (2014), Case Study Research: Design and Methods, Sage, Thousand Oaks.

Author contributions: All the authors contribute equally to this paper. 